\title{
Ultrasound examination of coelomic viscera through the plastron in stranded green sea turtles (Chelonia mydas)
}

\author{
Mariella Baldini ${ }^{1}$, Caroline Augusto Roque ${ }^{2, *}$, Melissa Marcon ${ }^{3}$ and Andrea Maranho ${ }^{4}$ \\ ${ }^{1}$ Centro Pellegrini de Medicina Veterinária, Rua Alexandre Herculano, 233, Gonzaga, Santos, SP, Brazil \\ ${ }^{2}$ Omega Imagem Veterinária, Av. Dr Bernardino de Campos, 533, Gonzaga, Santos, São Paulo, Brazil \\ ${ }^{3}$ Instituto Gremar pesquisa, educação e gestão de fauna Rodovia Ariovaldo de Almeida de Viana, Guarujá, São \\ Paulo, Brazil \\ ${ }^{4}$ Instituto Gremar pesquisa, educação e gestão de fauna Rodovia Ariovaldo de Almeida de Viana, Guarujá, São
}

Paulo, Brazil

\begin{abstract}
Many projects have been developed in the last years for the conservation of sea turtles. Young green turtles (Chelonia mydas) often nest on the Brazilian coast. Because they nest in beaches along the coastline and islands, green turtles are susceptible to fishing and accidental ingestion of anthropogenic debris. Early detection of ingested debris is crucial for the survival of rescued sea animals. Ultrasound (US) has emerged as a viable imaging technique for visceral examination in veterinary medicine. Previous studies have suggested the left and right cervicobrachial, axillary, preand post-femoral areas as the only viable approaches for US examination, but the acoustic windows available for imaging of coelomic structures are limited. It is important to notice that a detailed evaluation of all gastrointestinal tracts, especially the duodenum, is crucial for detecting foreign bodies and intestinal obstructive processes, as well as obtaining essential information such as intestinal motility and heart frequency. Intestinal motility and heartbeats are not detected through radiographic examination or through the acoustic windows available so far. This study aimed to establish the viability of US examination of coelomic viscera through the plastron in stranded green turtles. Eleven young green turtles rescued by the GREMAR Institute were examined. Turtles were placed in the dorsal decubitus position during US examination, which did not require anesthesia. Even though the plastron is constituted of bones and cartilage, the present research has proven the viability of obtaining US images through it, making it possible to visualize structures undetectable through the acoustic windows previously suggested. The following organs were evaluated through the plastron: heart, stomach, duodenum, jejunum, colon, liver, gallbladder, kidneys, bladder, and spleen (in case of splenomegaly). US imaging through the plastron is a viable approach for detecting ingested artificial debris, which represents one of the leading causes of death among sea turtles.
\end{abstract}

Keywords: Chelonia mydas, Green turtles, Plastron, Ultrasound.

\section{Introduction}

The sea turtle is one of the species protected by the International Union for Conservation of Nature. There are seven living species of sea turtles; one of the family Dermochelyidae (Dermochelys coriacea) and six of the family Cheloniidae: green turtle (Chelonia mydas), loggerhead sea turtle (Caretta caretta), hawksbill sea turtle (Eretmochelys imbricata), olive ridley sea turtle (Lepidochelys olivacea), Kemp's ridley sea turtle (Lepidochelys kempii), and Australian flatback sea turtle (Natator depressa) (Davenport, 1997; Soslau et al., 2005). Five of the seven sea turtle species are found along the Brazilian coastline: C. mydas, E. imbricata, L. olivacea, C. caretta, and D. coriacea. Brazilian law has protected the latter since 1986 (Marcovaldi and Marcovaldi, 1999; Baptistotte et al., 2003).

The green turtle is the most common sea turtle in Brazilian coastal waters (Ernest and Barbour, 1989).
Fishing bycatch and the ingestion of anthropogenic debris represent the two greatest threats to these animals (Bugoni et al., 2001; Magalhães et al., 2012). The incidental fishing bycatch in coastal and oceanic fisheries is one of the major causes of injury or death of a considerable number of turtles (Hall et al., 2000). Their distribution extends from tropical to temperate seas worldwide. Green turtles have benthic life habits and can dive to a depth of $20 \mathrm{~m}$. They nest in beaches along the coastline and islands of Brazil (Hirth, 1997). For the juvenile green turtles in the State of Sao Paulo, which is located in the southeast of Brazil, the mean curve carapace length is $41.7 \mathrm{~cm}$, the mean curved carapace width (CCW) is $38.3 \mathrm{~cm}$, and the mean weight is $9.2 \mathrm{~kg}$ (Aquatic biota monitoring information system-SIMBA, 2018). Green turtles migrate long distances between feeding grounds and hatching beaches often crossing entire oceans. A single female can lay more than 500 eggs per nesting season spread 


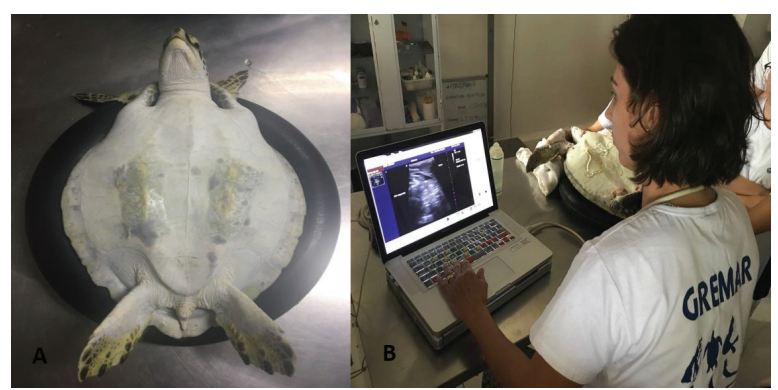

Fig. 1. (a) Green turtle placed in the dorsal decubitus position on an inflated tire inner tube. (b) Turtle placed next to the US system with the head alongside the equipment and the tail next to the examiner's right arm.

over 3-6 clutches at $15-\mathrm{d}$ intervals. The warmth of the sun and moisture of the sand serve to incubate the eggs for approximately $50 \mathrm{~d}$. The percentage of eggs hatched ranges between $50 \%$ and $80 \%$. From every 1,000 eggs, an estimated 1-2 hatchlings will reach adulthood (Baptistotte, 2014).

As all reptiles, sea turtles do not have a diaphragm to divide the thoracic from the abdominal cavity. Thus, they have a single coelomic cavity, containing all their viscera (Baptistotte, 2014). The cheloniid plastron is composed of four pairs of bones (epiplastron, hyoplastron, hypoplastron, and xiphiplastron) and one unpaired bone called entoplastron (Fig. 1a-c), which is as a key characteristic of this species (Wyneken, 2001). According to an Australian review that evaluated 37 studies published between 1985 and 2012, sea turtles from almost all areas ingest debris, especially plastic debris. These results indicate that ingestion of anthropogenic debris by sea turtles represents a global threat to these animals. Plastic objects are known to be fatal, killing sea life by blocking their stomach and causing malnutrition, or by puncturing their intestines (Schuyler et al., 2013).

Previous studies have recommended the left and right cervicobrachial, axillary, pre-femoral and post-femoral areas as the only viable approaches for ultrasound (US) examination of turtles. However, the acoustic windows available through such approaches for imaging of coelomic structures are limited, making it impossible to assess large part of the viscera. Thus, the present study aimed at establishing the viability of US examination through the plastron, which would enable broad visibility of the viscera in the coelomic cavity. Because US provides a dynamic diagnostic technique, the entire coelomic cavity can be assessed in real time, providing important and precise information such as heart frequency and the presence or absence of intestinal peristalsis in cases of obstruction by anthropogenic debris ingestion.

\section{Materials and Methods}

All examined animals were found stranded on the beach. Green sea turtles were rescued by GREMAR
Institute personnel as part of the Santos Basin Beach Monitoring Project, required for the federal environmental licensing conducted by IBAMA. The carcass of a recently deceased young green turtle was used to establish base parameters of structures visible through the plastron on US. The turtle had drowned and could be used as a test case because the causa mortis had not affected US condition of body structures. The interobserver study was conducted by two veterinarians specialized in imaging diagnosis with over $10 \mathrm{yr}$ of experience. US examination was performed before and during necropsy of the carcass and on 10 live young green turtles (3-8 yr of age) found on the Baixada Santista coast, São Paulo, southeast Brazil. The 10 green turtles examined had an average body weight of $10 \mathrm{~kg}, 45 \mathrm{~cm}$ of curved carapace length, $40 \mathrm{~cm}$ of CCW, and $54 \mathrm{~cm}$ total length.

A Terason $^{\mathrm{TM}}$ T3000 US system (Terason, Burlington, MA) with a linear multi-frequency transducer (frequency range: 7-12 MHz) was used for US examination.

The turtles were placed in the dorsal decubitus position on an inflated tire inner tube (Figure 1a) to the right of the US imaging system with the head placed alongside the equipment and the tail next to the examiner's right arm (Figure 1b). US gel at room temperature was evenly applied on plastrons before scanning of the coelomic cavity.

\section{Results}

US examination of the coelomic cavity of green turtles enabled the visualization of the following organs: heart, stomach, duodenum, jejunum, colon, kidneys, liver, spleen (in case of splenomegaly), and bladder. The plastron bones (epiplastron, entoplastron, hypoplastron, hyoplastron, and xiphiplastron) were used as references (Figure 2).

\section{Heart}

On longitudinal scans, the heart was observed between the epiplastron and hyoplastron bilaterally, next to the ventral midline. Three heart chambers, two atriums, and one ventricle were observed with a mean heartbeat rate of 38 to $50 \mathrm{bpm}$ (Figure 3).

\section{Stomach}

On longitudinal scans, the stomach was seen through the left hyoplastron, which was often distended with food and gas. Stratified walls measuring approximately $0.35 \mathrm{~cm}$ in thickness were observed (Figure 4).

\section{Duodenum}

The duodenum was observed through the right hyoplastron, medially and cranially to the stomach. It was usually filled with gas or fluid. We observed stratified walls measuring approximately $0.30 \mathrm{~cm}$ in thickness (Figure 5).

\section{Jejunum}

The jejunum was observed bilaterally through the hypoplastron and was usually filled with pasty content. Stratified walls measuring approximately $0.25 \mathrm{~cm}$ in 


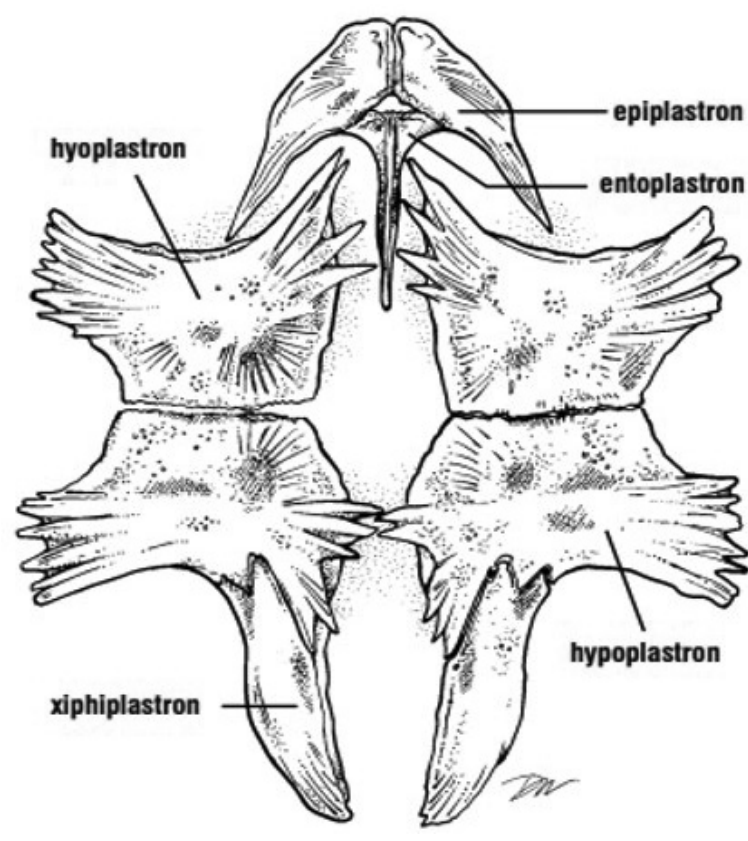

Fig. 2. Anatomical composition of the green turtle plastron.

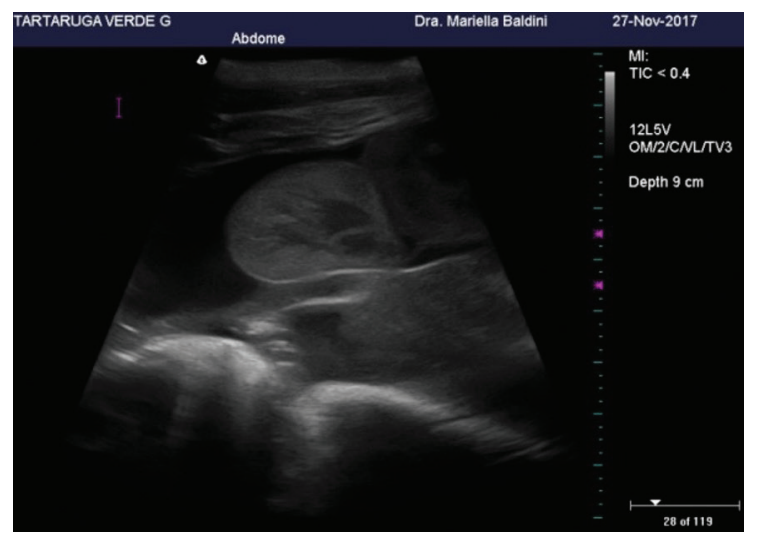

Fig. 3. Longitudinal scan of the heart.

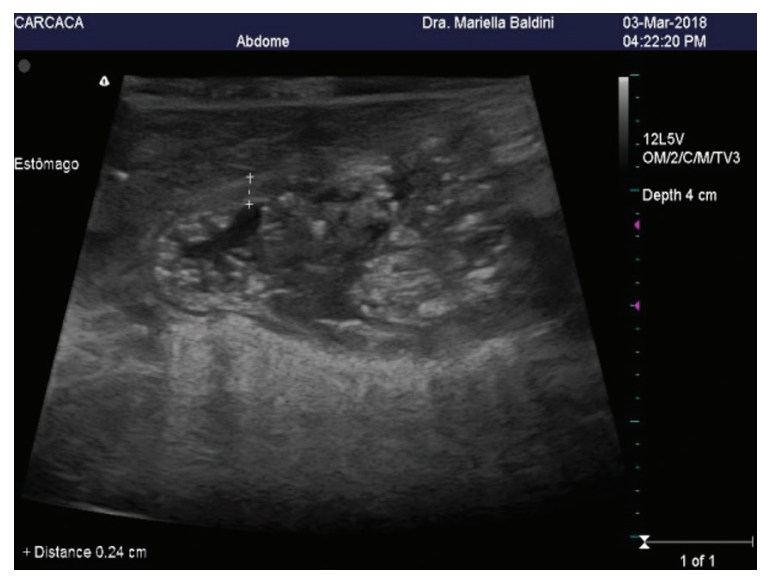

Fig. 4. Transverse US scan showing gastric wall thickness.

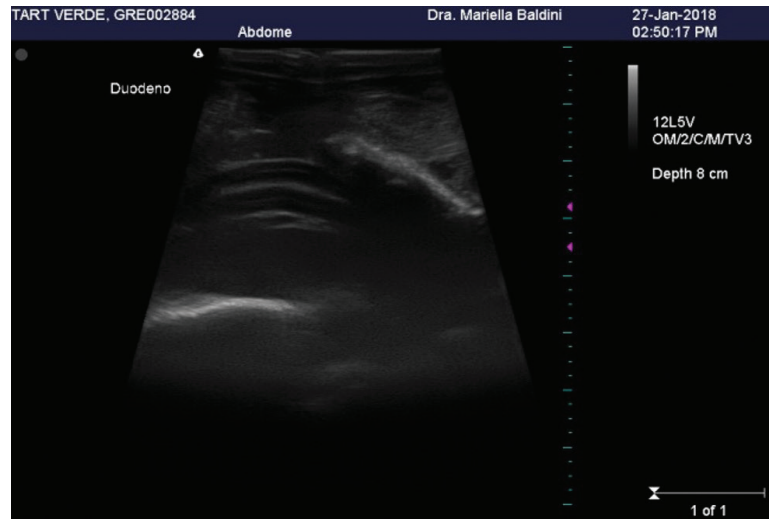

Fig. 5. Longitudinal scan of the duodenum.

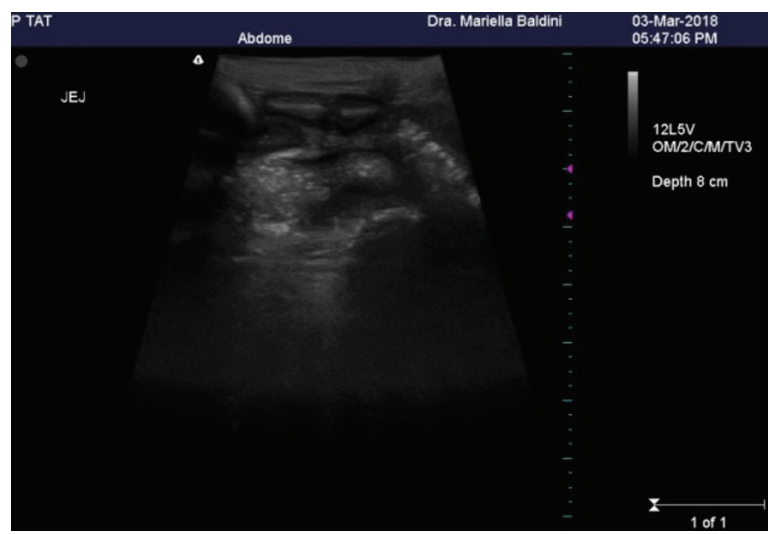

Fig. 6. Transverse US scan of jejunal segments.

thickness were observed (Figure 6). Masses of hardened feces obstructing the intestines, named fecalomas, were frequently found in the bowel.

\section{Colon}

On longitudinal scans, the colon was seen through the right hyoplastron and also through the pre-femoral space. Heterogenic fecal content was often present. Stratified walls measuring approximately $0.40 \mathrm{~cm}$ in thickness were observed (Figure 7a). In some of the turtles rescued by the GREMAR Institute, the bowel was distended due to the presence of large amounts of anthropogenic debris, leading to complete obstruction of the intestines and frequently causing death (Figure $7 \mathrm{~b}$ and $\mathrm{c})$.

\section{Kidneys}

Kidneys are retroperitoneal; on longitudinal scans, they were seen through the right and left pre-femoral space. Their ends are tapered and because they are multilobed, kidneys have slightly irregular borders, rough echotexture, and high echogenicity compared to the spleen, as observed here (Figure 8).

Liver

The liver was seen through the right hyoplastron; it had a smooth profile, tapered ends, homogeneous parenchyma, slightly rougher echotexture, and 


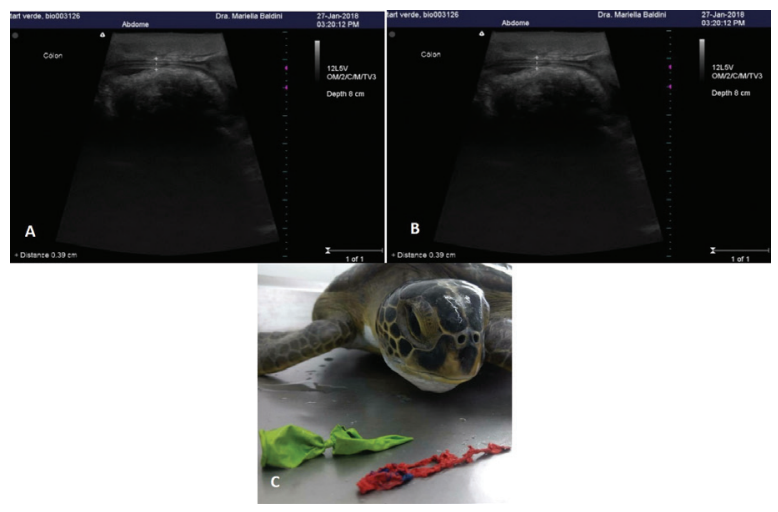

Fig. 7. (a) US image showing normal colon wall thickness; (b) Foreign body in the colon; and (c) Debris (rubber and plastic) expelled with green turtle's feces.

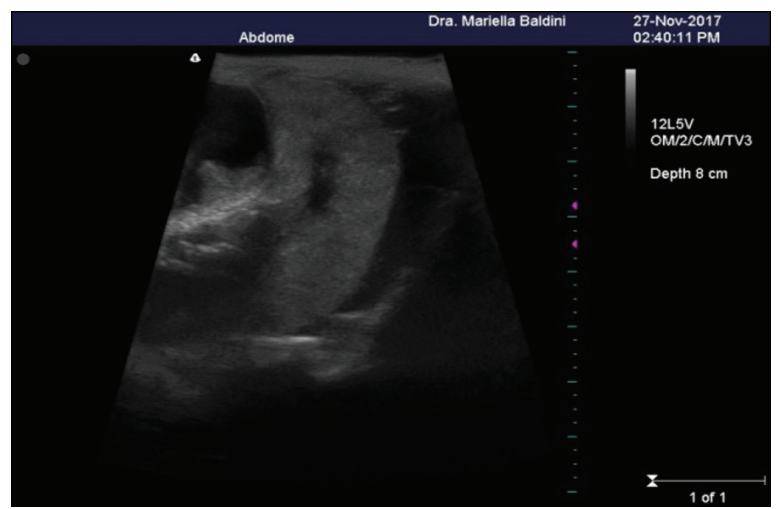

Fig. 8. US image showing normal left kidney, with tapered ends, rough echotexture, and high echogenicity compared to the spleen.

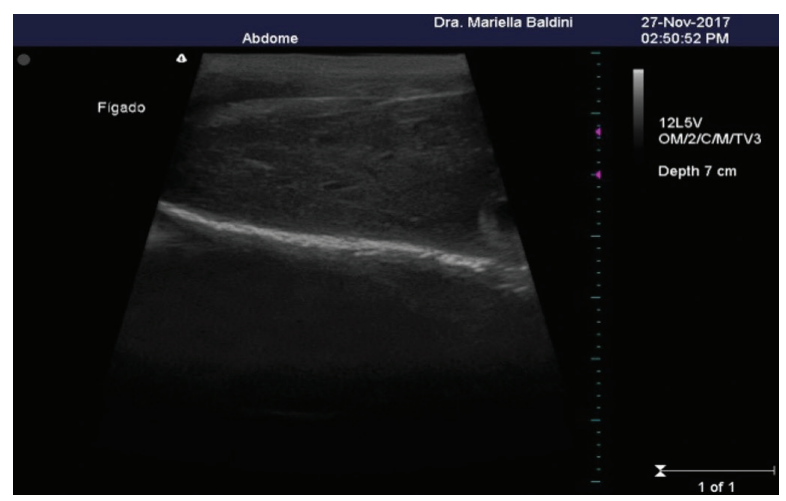

Fig. 9. Oblique longitudinal scan of the liver parenchyma.

slightly reduced echogenicity compared to the splenic parenchyma (Figure 9). The uniform appearance of the hepatic parenchyma was only disturbed by the presence of several tubular anechoic structures of varying caliber representing the portal and hepatic

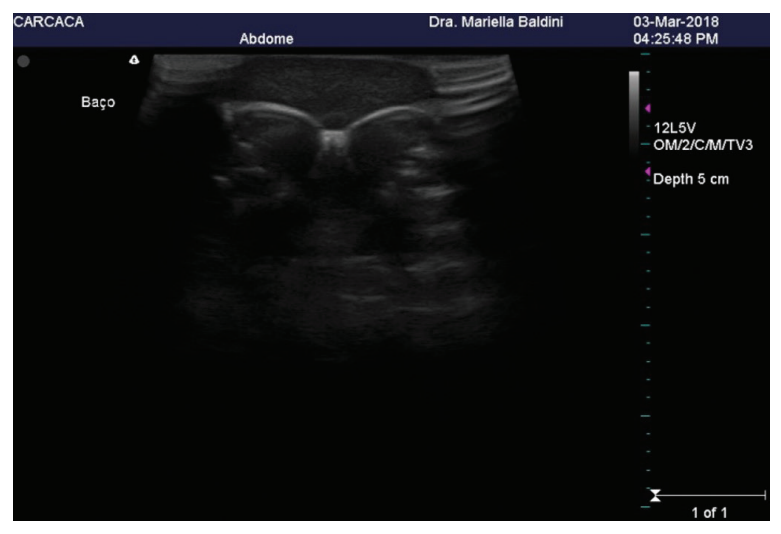

Fig. 10. US imaging of the spleen, which extends across the superior edge of the figure and displays homogeneous parenchyma, smooth echotexture, and slightly higher echogenicity compared to the liver parenchyma.

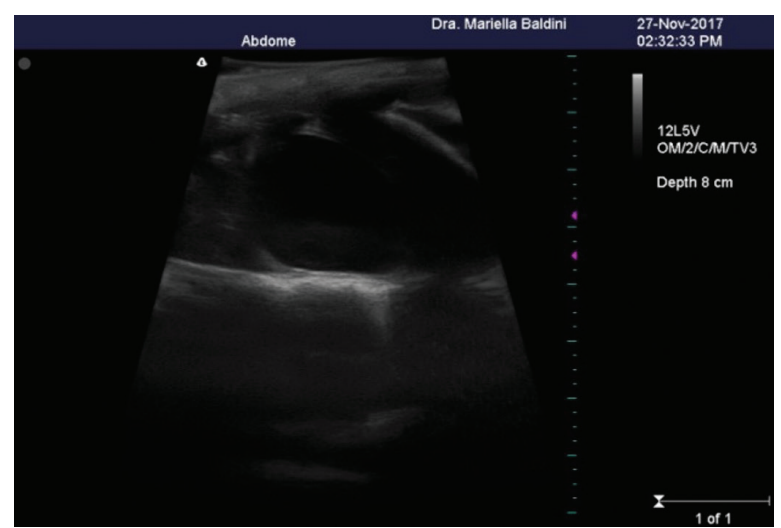

Fig. 11. US image of the urinary bladder, which is pearshaped, thin-walled, and filled with homogeneous anechoic content.

vessels. The gallbladder had an oval shape, thin walls, and homogeneous anechoic content.

Spleen

The spleen was difficult to visualize in vivo by US due to its small size and varying location. The spleen was oval or triangular shaped with a fine homogeneous echotextured parenchyma surrounded by a thin hyperechoic capsule and slightly higher echogenicity compared to the hepatic parenchyma (Figure 10).

\section{Urinary bladder}

On longitudinal scans, the urinary bladder was seen between the two xiphiplastrons: pear-shaped and thinwalled; the bladder often displayed a small amount of homogeneous anechoic content (Figure 11).

\section{Discussion}

The ingestion of anthropogenic debris including plastic, fishing items, glass, and rubber represents the leading cause of death among sea turtles (Bjorndal, 1997; Isenbugel et al., 1981). US emerges as the ideal 
examination technique to identify the gut contents of stranded sea turtles. Precisely diagnosing the presence of artificial debris in the GI system of sea turtles is extremely important because GI tract obstruction due to debris ingestion in marine animals may occur even when small amounts are ingested, potentially causing death (Bjorndal, 1997). The higher prevalence of fecalomas in stranded sea turtles is also associated with debris ingestion.

An US study performed in sea turtles using a multifrequency transducer $(3.5-7.5 \mathrm{MHz})$ concluded that the only acoustic windows available for imaging of the coelomic cavity were through the left and right cervicobrachial, left and right axillary, left prefemoral, and right post-femoral areas (Majo et al., 2016). Similarly, Wilkinson et al. (2003) argued that the carapace and plastron limit auscultation, palpation, and examinations such as US and X-rays. However, in the current study, we showed that US examination through the plastron is viable, providing visualization of the entire coelomic cavity and important and precise information such as heart rate and GI motility. The only structures that could not be identified through the plastron were the spleen, pancreas, adrenal glands, and gonads due to their small size and posterior overlapping of surrounding viscera. The entoplastron hinders the evaluation of structures located in the middle and cranial portion of the coelomic cavity because of its higher density and the presence of posterior acoustic shadowing.

The advantages and clinical applications of diagnostic US in veterinary medicine are well established, and US also plays a valuable role in sea animal research. However, few researchers have used the B-mode US on sea turtles, and even fewer have reported their results, explaining the scarcity of reference material.

US is a valuable tool that can be used as a complementary technique to physical and radiographic examination when additional information about internal structures is required. Portable US requires minimal handling of animals and can be taken to the animal enclosure, thus preventing the transfer of turtles that are often weak to a diagnostic laboratory for radiographic examination. $\mathrm{X}$-rays often provide insufficient information about coelomic structures, with the exception of the lungs.

US is a simple, safe, and cost-effective diagnostic technique. Due to its non-invasive and non-radiating nature, it can be easily adapted to any working environment to provide an accurate and extensive range of morphological and morphometric information. US examination of coelomic viscera through the plastron using a standard transducer enables visualization of morphological and morphometric features of various coelomic organs of stranded green turtles.

\section{Conflict of interest}

The authors declare that there is no conflict of interest.

\section{References}

Baptistotte, C. 2014. Tratado de Animais Selvagens. In: Medicina Veterinária. Eds., Cubas Z.S., Silva J.C.R., Dias J.L.C., pp: 260-270.

Baptistotte, C., Thomé, J.C.A. and Bjorndal, K.A. 2003. Reproductive biology and conservation status of the loggerhead sea turtle (Caretta caretta) in Espírito Santo Estate, Brazil. Chelonian Conserv. Biol. 4(3), 523-529.

Bjorndal, K.A. 1997. In The Biology of Sea Turtle. Eds., Lutz, P.L. and Musick, J.A., pp: 199-231.

Bugoni, L., Krause, L. and Petry, E.M.V. 2001. Marine debris and human impacts on sea turtles in southern Brazil. Mar. Pollut. Bull. 41, 1338-1342.

Davenport, J. 1997. Temperature and the life-history strategies of sea turtles. J. Ther. Biol. 22, 479-488.

Ernest, C.H. and Barbour, R.W. 1989. Turtle of the world, 1st ed. Washington, WA: Smithsonian Institution Press.

Hall, M.A., Alverson, D.L. and Metuzals, K.I. 2000. By-catch: problens and solutions. Mar. Pollut. Bull. 4, 204-219.

Hirth, H.F. 1997. Synopsis of the biological data on the green turtle, Chelonia mydas (Linnaeus 1758). Washington, WA: United States Fish and Wildlife Service Biological Report.

Isenbugel, E., Barandun, G. 1981. Surgical removal of a foreign body in a bastard turtle. Vet. Med. Small Anim. Clin. J. 76, 1766-1768.

Magalhães, M.S., Santos, A.J.B., Silva, N.B. and Moura, C.E.B. 2012. Anatomy of the digestive tube of sea turtles (Reptilia: Testudines). Zoologia. 29, $70-76$.

Majo, M.D., Macri, F., Masucci, M., Coci, G. and Pennisi. M.G. 2016. Clinical ultrasonography in loggerhead sea turtles (Caretta caretta): imaging of pathological features. Department of Veterinary Sciences. Vet. Med. 61(3), 155-161.

Marcovaldi, M.A. and dei Marcovaldi, G.G. 1999. Marine turtles of Brazil: the history and structure of the Projeto TAMAR-IBAMA. Biol. Conserv. 91, $35-41$.

Schuyler, Q., Hardesty, B.D., Wilcox, C. and Townsend, K. 2013. Global analysis of anthropogenic debris ingestion by Sea Turtles. Conservat. Biol. 28(1), 129-139.

SIMBA. 2018. Software-Sistema de informação de monitoramento de biota aquática (Aquatic biota monitoring information system). Available via: https://segurogis.petrobras.com.br/simba/web/

Soslau, G., Prest, P.J., Class, R., George, R., Paladino, F. and Violettaa, G. 2005. Comparison of sea turtles thrombocyte aggregation to human platelet aggregation in whole blood. Comp. Biochem. Physiol. 142, 353-360. 
Wilkinson, R., Hernandez-Divers, S. J., Lafortune, M. Calvert, I., Gumpenberger, M. and McArthur, S. 2003. Diagnostic imaging techniques. In Medicine and Surgery of Tortoises and Turtles.
Eds., McArthur, S.M., Wilkinson, R. and Meyer, J. Oxford, UK: Black-well Publishing. pp: 187-239.

Wyneken, J. 2001. The anatomy of sea turtles. Miami, FL: U.S. Department of Commerce NOAA Technical Memorandum NMFS-SEFSC-470. 